\title{
Atuação do conselho estadual da pessoa idosa de Minas Gerais frente à pandemia da covid-19
}

O envelhecimento populacional acelerado impõe desafios sociais, políticos, econômicos e culturais, os quais podem apresentar maior dificuldade de enfrentamento durante uma situação emergencial, colocando em xeque os dispositivos legais, os órgãos e as instituições voltadas ao atendimento da população idosa. Assim, o objetivo deste artigo é compreender a atuação do Conselho Estadual da Pessoa Idosa de Minas Gerais (CEI MG) frente à pandemia da Covid-19. Para tanto, foi desenvolvida uma pesquisa qualitativa descritiva de cunho exploratório, por meio de estudo de caso. Foi utilizada a triangulação de fontes para a obtenção dos dados da pesquisa, valendo-se de pesquisa documental, entrevistas semiestruturadas e observação não participante. Como resultado, verificou-se que, além de ajustes na forma de seu funcionamento, o Conselho tem se valido do empenho dos seus membros e de parceiros, instituições governamentais, não governamentais e sociedade civil, para viabilizar ações imediatas de suporte à população idosa de Minas Gerais. Concluiu-se que apesar das dificuldades oriundas do momento de crise sanitária e de entraves burocráticos governamentais, o Conselho tem conseguido efetivar o atendimento à parcela da população idosa mineira considerada mais vulnerável, qual seja, a de moradores de Instituições de Longa Permanência para Idosos, oportunizando lhe informações e serviços para o enfrentamento da Covid-19.

\section{Performance of the state council of elderly people of Minas Gerais in front of the covid-19 pandemic}

\begin{abstract}
Accelerated population aging imposes social, political, economic and cultural challenges, which can be more difficult to cope with during an emergency situation, calling into question the legal provisions, the organs and institutions aimed at serving the elderly population. Thus, the objective of this article is to understand the role of the State Council for the Elderly of Minas Gerais (CEI MG) in the face of the Covid-19 pandemic. To this end, a descriptive qualitative research of an exploratory nature was developed, through a case study. The triangulation of sources was used to obtain the research data, using documentary research, semistructured interviews and non-participant observation. As a result, it was found that, in addition to adjustments in the way it works, the Council has used the efforts of its members and partners, governmental, non-governmental institutions and civil society, to enable immediate actions to support the elderly population of Minas Gerais. It was concluded that despite the difficulties arising from the moment of sanitary crisis and government bureaucratic obstacles, the Council has managed to provide assistance to the portion of the elderly population of Minas Gerais considered to be more vulnerable, that is, that of residents of Long Term Care Institutions for the Elderly, providing information and services for coping with Covid-19.
\end{abstract}

Keywords: State Council for the Elderly of Minas Gerais; Elderly; Pandemic; Covid-19.

Topic: Gestão Pública

Reviewed anonymously in the process of blind peer
Received: 07/01/2021

Approved: 22/03/2021

Roseany Gloriane Mendes (iD

Universidade Federal de Viçosa

http://lattes.cnpq.br/4587981402145303

http://orcid.org/0000-0002-4034-126X

roseanymendes@gmail.com

Gustavo Marcílio Vieira da Silva (iD)

Universidade Federal de Viçosa

http://lattes.cnpq.br/6738316500296361

http://orcid.org/0000-0003-4595-8565

gustavomarciglio@gmail.com

Simone Martins (D)

Universidade Federal de Viçosa

http://lattes.cnpq.br/5311862771207808

http://orcid.org/0000-0002-6614-4811

simone.m@ufv.br

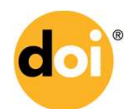

Referencing this:

DOI: 10.6008/CBPC2179-684X.2021.001.0013

MENDES, R. G.; SILVA, G. M. V.; MARTINS, S.. Atuação do conselho estadual da pessoa idosa de Minas Gerais frente à pandemia da covid19. Revista Brasileira de Administração Científica, v.12, n.1, p.158169, 2021. DOI: http://doi.org/10.6008/CBPC2179684X.2021.001.0013 


\section{INTRODUÇÃO}

Atualmente, presencia-se no mundo um processo acelerado de envelhecimento populacional, no qual as taxas de fecundidade e mortalidade infantil declinam e a taxa de longevidade aumenta, conforme resultados do Global Burden of Disease (2017). Neste contexto de novo paradigma, é inevitável o surgimento de desafios sociais, políticos, econômicos e culturais. No Brasil, segundo o Instituto Brasileiro de Geografia e Estatística (IBGE), 13\% da população é idosa, ou seja, mais de 28 milhões de pessoas. Em Minas Gerais, as pessoas idosas representam $16,4 \%$ da população, cerca de 3,4 milhões de pessoas, e a previsão, segundo o IBGE, é que, até 2060, Minas Gerais seja o estado com o maior número de idosos do país, serão $28,7 \%$ da população local contra $25,5 \%$ da média nacional.

Segundo Martins et al. (2018), desde a década de 80, surgiram no Brasil assembleias e movimentos que marcaram o estabelecimento de políticas públicas para as pessoas idosas. Por exemplo, a Lei № 10.741, de 1 으 de outubro de 2003, Estatuto do Idoso, que em seu artigo 3o prevê a obrigação não apenas da família, mas também da comunidade, da sociedade e do poder público para assegurar ao idoso, com absoluta prioridade, "a efetivação do direito à vida, à saúde, à alimentação, à educação, à cultura, ao esporte, ao lazer, ao trabalho, à liberdade, à dignidade, ao respeito e à convivência familiar e comunitária" (BRASIL, 2003).

Após a identificação, na China, do vírus SARS-CoV-2, novo coronavírus, causador da doença denominada Covid-19, com rápida contaminação mundial e, em seguida, da caracterização desta como pandemia pela Organização Mundial da Saúde (OMS), em 11 de março de 2020, foi adotado também no Brasil o distanciamento social como uma das principais formas de prevenção da doença, conforme sugerido por órgãos de saúde internacionais e nacionais. Ainda, de acordo com a OMS, adultos com mais de sessenta anos e pessoas com doenças preexistentes têm maiores riscos de ter a doença agravada, ao contrair a Covid19. De tal forma, medidas de prevenção e proteção devem ser preconizados eficazmente na redução das já conhecidas formas de contágio em todos os locais. Em publicação da Associação Brasileira de Saúde Coletiva, é notada uma preocupação com as diversas vulnerabilidades e fragilidades às quais as pessoas idosas estão sujeitas, com um olhar também voltado aos idosos em situação de rua, aos que vivem do trabalho informal e aos que vivem em Instituições de Longa Permanência para Idosos (ILPIs). Estudos preliminares sobre idosos institucionalizados apontam que, nestas realidades, a infecção pelo SARS-CoV-2 é alta, com sugestão de taxa de mortalidade para maiores de oitenta anos superior a 15\% (HAMMERSCHMIDT et al., 2020). Além disso, revelam a fragilidade destas instituições em usufruir de recursos necessários ao enfrentamento da doença, seja pela insuficiência de recursos humanos, por meio de profissionais de saúde, seja por escassez de recursos financeiros e materiais, como apontam Martins et al. (2020).

Em situações emergenciais, o funcionamento dos dispositivos legais, órgãos e instituições que cuidam da população pode ficar fragilizado, principalmente quando se trata de um cenário de problema de saúde mundial. Dadalto et al. (2020) consideram que o contexto da pandemia gerou um aprofundamento das possíveis práticas de ageísmo, ou seja, práticas e falas discriminatórias em relação aos idosos, na área da saúde, em razão da insuficiência de recursos disponíveis para o enfrentamento da Covid-19. E apontam que 
as normas de proteção internacionais têm se mostrado insuficientes para tutelar os idosos de atos e práticas discriminatórias, razão pela qual defendem que cada Estado Nação crie seus próprios mecanismos de proteção e que haja a adoção de uma convenção internacional específica contra o ageísmo.

Neste contexto, cabe verificar a observância e a garantia dos direitos das pessoas idosas por parte do poder público e da sociedade civil, no momento da pandemia da Covid-19. Neste trabalho, objetiva-se compreender a atuação do Conselho Estadual da Pessoa Idosa de Minas Gerais (CEI MG), por se tratar de um órgão deliberativo e controlador das políticas e das ações voltadas ao idoso de âmbito estadual, composto por representantes do Estado e da sociedade civil. Para tanto, serão levantadas as ações do Conselho no enfrentamento à Covid-19 e os principais facilitadores e desafios encontrados pelo órgão para a execução dessas ações.

\section{REVISÃO TEÓRICA}

\section{Conselhos gestores}

Avritzer (2008) aponta que uma das formas de instituições participativas se constituírem ocorre por meio de um processo de partilha do poder decisório, isto é, da constituição de uma instituição na qual atores estatais e da sociedade civil participam de forma simultânea. Os avanços constitucionais no desenho das políticas sociais criaram espaços de participação da sociedade no planejamento e na execução de políticas por meio de conselhos municipais, estaduais e federais (ROCHA, 2008).

Os conselhos, que podem ser consultivos ou deliberativos, conforme Carneiro (2002), são espaços públicos não-estatais que sinalizam a possibilidade de representação de interesses coletivos na cena política e na definição da agenda pública, apresentando um caráter híbrido, uma vez que são, ao mesmo tempo, parte do Estado e da sociedade; apresentam estrutura legalmente definida e institucionalizada, cuja razão de ser reside na ação conjunta com o aparato estatal na elaboração e gestão de políticas sociais. A autora considera que a questão dos conselhos se insere fundamentalmente na área da governança democrática e acrescenta que, como canais institucionalizados de participação, marcam uma reconfiguração das relações entre Estado e sociedade e instituem uma nova modalidade de controle público sobre a ação governamental, idealmente, de corresponsabilização quanto ao desenho, o monitoramento e a avaliação de políticas (CARNEIRO, 2002).

Ainda segundo Carneiro (2002), os conselhos permitem maior grau de acerto no processo de tomada de decisões e ajudam na identificação mais rápida de problemas e na construção de alternativas de ação, aumentado a transparência administrativa e pressionando as diversas áreas do governo em direção a ações mais integradas. Fonseca (2011) destaca importantes regras que devem ser claramente estabelecidas para a ordenação do debate e do processo decisório dos conselhos, a fim de aperfeiçoar tais espaços como instâncias participativas, são tais regras o estabelecimento dos critérios de paridade entre governo e sociedade civil, as regras para a eleição livre de conselheiros e, ou, para o exercício da presidência ou instância similar, e a garantia de espaços e posições ocupadas por atores locais. 
Trazendo a questão para o contexto da pessoa idosa, Gohn (2006) destaca que os conselhos gestores de direitos desta população, como cogestores, abrem a possibilidade de a sociedade civil intervir na gestão pública via parcerias com o Estado, que objetivem a formulação e o controle de políticas sociais que zelem pelos direitos da pessoa idosa.

\section{Conselhos de direitos da pessoa idosa}

Os conselhos setoriais constituem importante oportunidade de participação social e política para a população idosa, devido à intrínseca ligação destes espaços com as políticas públicas e a oferta de assento à população, por meio da representação (BREDEMEIER, 2003). Dessa forma, percebe-se que os conselhos têm a possibilidade de empenho na luta pelo empoderamento e pela defesa dos direitos da pessoa idosa, uma vez que podem avançar na formulação de novos direitos e em sua implementação.

A Política Nacional do Idoso, Lei no 8.842, de 4 de janeiro de 1994, estabelece a criação de conselhos nacional, estaduais e municipais do idoso, sendo os conselhos órgãos permanentes, paritários e deliberativos, compostos por igual número de representantes dos órgãos e entidades públicas e de organizações representativas da sociedade civil ligadas à área. A eles compete a supervisão, o acompanhamento, a fiscalização e a avaliação da política nacional do idoso, no âmbito das respectivas instâncias. Pereira (2005) esclarece que os conselheiros governamentais são representantes das secretarias ou ministérios que tenham interface com o tema, podendo outras instituições governamentais também terem representação nesses espaços, como as universidades. Já os conselheiros da sociedade civil são pessoas que devem representar diferentes estratos institucionais que compõem o universo das organizações ou entidades não governamentais de ou para pessoas idosas, como usuários, trabalhadores, dirigentes e filiados classistas.

A autora aponta como principais objetivos dos conselhos de direitos da pessoa idosa, independente do âmbito de atuação, dentre outros, a defesa dos direitos da pessoa idosa previstos em lei e o zelo pelo cumprimento dos princípios da descentralização político-administrativa e da participação popular, bem como pela realização efetiva do comando único das ações governamentais e não-governamentais. Com relação ao funcionamento desses conselhos, de acordo com Pereira (2005), são as leis de criação dos órgãos que estabelecem orientações para a elaboração de seus regimentos internos, objetivos e competências, o número e a procedência de seus integrantes, a duração dos mandatos dos conselheiros, a periodicidade das reuniões, as comissões de trabalho, a alternância da representação governamental e não governamental, tendo como referência os princípios da paridade e da deliberação autônoma.

Estudos realizados por Debert et al. (2016) e Mallet (2015) apontam que, apesar de sua importância, a atuação dos conselhos nem sempre é satisfatória. Os problemas identificados dizem respeito à relação de interdependência com o poder público na obtenção de recursos, à dificuldade na manutenção da sua autonomia, a dificuldades na articulação entre sociedade civil e governo, também aos entraves no funcionamento da burocracia. Soma-se a isso o desconhecimento dos conselheiros sobre questões que envolvem o envelhecimento populacional, sobre suas funções e a falta de assiduidade nas reuniões. 
Na seção 4 será apresentado o Conselho Estadual da Pessoa Idosa de Minas Gerais, objeto deste estudo.

\section{METODOLOGIA}

Para o desenvolvimento deste trabalho, quanto aos objetivos e à abordagem do problema, foi realizada uma pesquisa qualitativa descritiva de cunho exploratório, em consonância com o que aponta Godoy (1995) e Silveira et al. (2009), por se tratar de examinar um tema ou problema de investigação pouco estudado, em seu ambiente natural, tendo a palavra escrita lugar de destaque tanto no processo de obtenção dos dados quanto na disseminação dos resultados. Quanto à estratégia, adotou-se o estudo de caso, pois, segundo Yin (2015), tal método responde a questões de pesquisa "como", não exige o controle de eventos comportamentais e tem enfoque em eventos contemporâneos. Assim, por ser a pandemia da Covid-19 um tema vivenciado neste momento pela população mundial, o entendimento de como está a atuação do Conselho Estadual da Pessoa Idosa de Minas Gerais neste contexto é um tema ainda não explorado.

Com relação à coleta de dados, ocorrida nos meses de maio a agosto de 2020, utilizou-se, inicialmente, a pesquisa documental, pelo fato de possibilitar a análise de documentos que contém informações sobre o fenômeno de que deseja estudar bem como a obtenção de informações que não existem em livros (GARCIA et al., 2016). Optou-se pela pesquisa documental também por ela permitir acrescentar a dimensão do tempo à compreensão do social, favorecendo a observação do processo de maturação ou de evolução de indivíduos, grupos, conceitos, conhecimentos, comportamentos, entre outros (SÁ-SILVA et al., 2009). Neste sentido, para a verificação da veiculação de notícias sobre o tema estudado pelo Conselho, foram consultadas as publicações do sítio eletrônico (site) do próprio Conselho, da Secretaria Estadual de Desenvolvimento Social, do Sistema Estadual de Redes em Direitos Humanos, do Diário Oficial, todos do Estado de Minas Gerais, do Jornal Estado de Minas e do Portal Uai, referentes ao período de janeiro a agosto de 2020 .

Outro método de coleta de dados utilizados foi a entrevista com membros do CEI MG. Optou-se pela entrevista, pois, segundo Duarte (2005), tal técnica qualitativa explora um assunto a partir da busca de informações, percepções e experiências de informantes para analisá-las e apresentá-las de forma estruturada, além disso, o uso da entrevista permite identificar as diferentes maneiras de perceber e descrever os fenômenos. Pelo fato de o objeto de estudo ser um órgão composto por representantes da sociedade civil e do governo do estado, foram entrevistados três representantes de cada segmento, nos meses de junho e agosto, sendo três mulheres e três homens, ocupantes de diferentes funções no Conselho. Duarte (2005) esclarece que nos estudos qualitativos são preferíveis poucas fontes, mas de qualidade. Para o autor, é importante obter informações que possam dar visões e relatos diversificados sobre os mesmos fatos. Metade dos entrevistados está no CEI MG há, no máximo, um ano, enquanto os demais possuem acima de quatro anos de experiência. A fim de orientar as entrevistas, realizadas via aplicativo de videoconferência, em função da pandemia e do distanciamento social por ela requerido, utilizou-se um roteiro composto por questões abertas, que permitiu uma organização flexível e a ampliação dos questionamentos à medida que 
as informações eram fornecidas pelos entrevistados. Em outras palavras, foram realizadas entrevistas semiestruturadas (BELEl et al., 2008), gravadas e transcritas.

A fim de obter informações complementares durante o período de realização da pesquisa, utilizouse a observação não participante, usada com bastante frequência como técnica exploratória, segundo Vianna (2003). Para tanto, um dos pesquisadores acompanhou as reuniões ordinárias do Conselho realizadas nos meses de junho a agosto e dois eventos virtuais, o comemorativo do Dia Mundial de Combate à Violência contra Pessoas Idosas (15 de junho) e o de apresentação das ações da Rede de Apoio à Pessoa Idosa (10 de agosto), de ambos participaram o presidente e o vice-presidente do Conselho. Pelo exposto, observa-se, o emprego da triangulação de fontes para a obtenção dos dados da pesquisa.

\section{RESULTADOS E DISCUSSÃO}

Nesta seção, serão apresentados e discutidos os resultados levantados pela pesquisa no que tange à organização e às ações do CEI MG no enfrentamento à Covid-19, da mesma forma que os principais facilitadores e desafios encontrados para a execução de tais ações.

\section{O conselho estadual da pessoa idosa de Minas Gerais}

O Conselho Estadual da Pessoa Idosa de Minas Gerais foi criado pela Lei no 13.176, de 20 de janeiro de 1999, como órgão deliberativo e controlador das políticas e das ações voltadas ao idoso de âmbito estadual. A Secretaria de Estado de Desenvolvimento Social (Sedese) presta ao CEI MG o assessoramento e o apoio administrativo necessários. Compete ao Conselho promover ações junto aos órgãos de segurança e de justiça para que a pessoa idosa receba atendimento especial e de qualidade. Sua composição é paritária entre o poder público e a sociedade civil, a exemplo do que pontua Fonseca (2011). São previstas onze cadeiras para o poder público e onze para a sociedade civil, estando ocupadas atualmente, oito e nove, respectivamente. Durante o ano de 2020, a presidência do Conselho tem sido exercida por representante da sociedade civil e a vice-presidência, por representante do Estado, de acordo com eleição realizada na primeira reunião do ano, ocorrida em 31 de janeiro. Assim como destacado por Pereira (2005), o Conselho trabalha com a alternância da representação na presidência. A função de membro do CEI MG é considerada de interesse público relevante e não remunerada.

De acordo com seu Regimento Interno, o Conselho deve formular e zelar pela Política Estadual dos Direitos do Idoso, indicar prioridades a serem incluídas no planejamento global do Estado em relação ao idoso, cumprir e fazer cumprir as normas constitucionais e legais referentes ao idoso, tal como incentivar e apoiar a realização de eventos, estudos, pesquisas voltadas ao idoso e à criação de oportunidades para o idoso no mercado de trabalho, em concordância com as considerações de Carneiro (2002). A ação do Conselho se dá também por meio da atuação de comissões temáticas, estando previstas as comissões de políticas públicas, normas e fiscalização, financiamento e fundo, e regionalização, temas sociais, municipalização. Essas competências e medidas, entretanto, são tomadas dentro de uma situação normal, com planejamento. Não há no regimento interno previsão de dispositivo que facilite o papel do CEI MG 
durante uma situação emergencial, como é o caso do enfrentamento à pandemia da Covid-19.

\section{O CEI MG diante da pandemia da covid-19}

Com relação à estrutura e ao funcionamento do CEI MG, conforme comunicado disponível em seu site e relatos dos entrevistados, em cumprimento ao disposto na Deliberação Extraordinária do Comitê Extraordinário Covid-19 no 02 do Estado de Minas Gerais, de 16 de março de 2020, o funcionamento do órgão tem ocorrido por meio de teletrabalho. As reuniões ordinárias e extraordinárias passaram a ser realizadas via aplicativo de videoconferência desde então. Na reunião ordinária de junho, foi aprovada nova versão do Regimento Interno, com a previsão de reuniões remotas, a fim de validar o formato. Os entrevistados informaram que o Conselho não considerou suspender suas atividades, por entender a imprescindibilidade de sua ação no momento.

Além das plenárias, outro propulsor das atividades são as comissões temáticas, previstas no CEI MG, em consonância com o que aponta Pereira (2005). Na nova versão do Regimento Interno foram estabelecidas as responsabilidades de cada comissão, o que não constava na anterior. Conforme falas ocorridas na reunião de aprovação, esperava-se que o documento ensejasse a composição e o início dos trabalhos dos grupos, não obstante, percebeu-se pelas plenárias de julho e agosto que isso não ocorreu.

Como iniciativas de enfrentamento, em março, antes mesmo que a pandemia fosse anunciada pela OMS, considerando o cenário que se apresentava, o CEI MG, por iniciativa de membros, elaborou um documento orientativo voltado aos conselhos e às prefeituras municipais, também disponibilizou em seu site um documento explicativo sobre o novo coronavírus. Além dessa, foram encontradas publicações do Conselho sobre a Covid-19 no site do Sistema Estadual de Redes em Direitos Humanos. No mês de julho, houve alterações no site, com a criação de um link na aba 'Serviços à População' denominado 'Covid-19' para publicações específicas sobre o tema. Nele, constam documentos emitidos pelo governo do estado, como notas técnicas e portarias, pesquisas visando o levantamento de informações que resultem em retorno aos respondentes, orientações para prevenção do contágio da doença e divulgação de eventos voltados ao público-alvo do Conselho, realizados por ele e pela Sedese em parceria com outros órgãos estaduais, instituições públicas e organizações privadas. Com estas ações informativas, entende-se que o Conselho colabora para o maior grau de acerto no processo de tomada de decisões de outros órgãos e ajuda na identificação mais rápida de problemas e na construção de alternativas de ação, em alinhamento com as considerações de Carneiro (2002) e Gohn (2006).

Outra iniciativa foi a destinação de parte do recurso do Fundo Estadual do Idoso (FEI), $\mathrm{R} \$ 500$ mil, para a aquisição de equipamentos de proteção individual e de alimentos para moradores de Instituições de Longa Permanência para Idosos, pelo fato de o Conselho considerar ser esse o público que mais precisa de atenção no atual contexto, devido a sua vulnerabilidade. A proposta de utilização do Fundo, registrada na Resolução no 02/2020 do Conselho, que estava publicada no site em maio e posteriormente foi retirada, era de realização de um chamamento público com dispensa de licitação, devido à urgência da situação, para que a entidade vencedora pudesse realizar a aquisição e distribuição dos itens solicitados às ILPIs e 
posteriormente realizasse a prestação de contas ao Estado. O levantamento das instituições a serem atendidas assim como suas demandas ficaria a cargo do CEI MG. Não se sabe, porém, quando esta ação poderá ser colocada em prática, dado que o governo do estado, baseado na Lei Complementar no 91, bloqueou a utilização de todos os fundos com recursos do tesouro estadual para fins que não de combate à pandemia. Todavia, vale destacar que o bloqueio não enquadra a proposição do Conselho, pois o recurso liberado se destina exatamente ao enfrentamento da Covid-19, conforme destacado pelos entrevistados. Além disso, o bloqueio do FEI não se deu exclusivamente diante da pandemia. Baseando-se na citada lei complementar, o Estado vem controlando o recurso, por considerá-lo sua posse, contudo, segundo os representantes do Conselho, o recurso do Fundo origina-se da contribuição de pessoas físicas e jurídicas, visando a dedução da doação em imposto de renda. Entrevistados destacaram que não se sabe como o governo teve acesso ao recurso do FEl, depositado em conta própria, e o alocou no caixa único do Estado, dificultando sobremaneira o acesso ao recurso em momento de necessidade, como o que se apresenta. Não há registros de como se deu tal transação, de quem as autorizou por parte do CEI MG. Assim, o Conselho entrou com ação no Ministério Público para 'reaver a posse' do recurso e o direito à sua administração. Devido a este imbróglio, ainda não houve, para nenhum fim, a utilização de recurso do FEl. Na reunião ordinária de julho, o Conselho aprovou um edital de chamamento público visando a captação de recursos para o Fundo, em mais uma tentativa de acessá-lo, após novas conversas e buscas por entendimento com o governo do estado. Diante o exposto, pode-se inferir a não observância, por parte do Estado, do inciso III § 10 do art. 3ำ da Lei 10.741/2003, que versa a "destinação privilegiada de recursos públicos nas áreas relacionadas com a proteção ao idoso" (BRASIL, 2003).

Como forma de contornar a burocracia e a morosidade dos processos públicos estaduais, o CEI MG e a Coordenadoria dos Direitos da Pessoa Idosa (Cepid), da Subsecretaria de Direitos Humanos da Sedese, tiveram a iniciativa de se unirem a instituições públicas federais de educação, à sociedade civil, a instituições não governamentais para viabilizar ações imediatas. Assim, juntamente com o corpo técnico de instituições de ensino, como a Universidade Federal de Viçosa, foram criadas a Rede de Apoio à Pessoa Idosa (Rapi) e a Rede de Solidariedade. A Rapi objetiva criar oportunidades para melhorar a qualidade de vida da população idosa, promover a sua autonomia, integração e participação efetiva na sociedade, e a coordenação do grupo está a cargo do Conselho e da Cepid. Já a Rede de Solidariedade visa assegurar o atendimento ao público idoso que se encontra em situação de vulnerabilidade econômica, com a arrecadação e distribuição de donativos. Valendo-se destas redes, formadas por diferentes atores governamentais e não governamentais, pode-se dizer que o Conselho utiliza da governança democrática para a sua atuação, apontada por Carneiro (2002) como central na matéria dos conselhos, bem como da governança colaborativa.

No mesmo sentido, o CEI MG requereu à Universidade Federal de Viçosa o levantamento da situação das ILPIs do estado. O diagnóstico foi realizado no mês de abril e, com base nos resultados, o Conselho, também a Cepid, demonstrando uma postura proativa e resolutiva, orientaram suas ações no sentido de atender às demandas apontadas pelas instituições. A Rapi passou a disponibilizar serviços que contemplam algumas das principais questões, como a orientação para regularização jurídica das ILPIs. No evento de 
apresentação das ações da Rapi, o presidente do Conselho destacou a importância das parcerias no combate à pandemia pelo órgão.

Atinente aos facilitadores e desafios identificados para a atuação do Conselho frente à pandemia, observou-se, devido à atipicidade da situação, principalmente no período inicial, que se apresentam com mais ênfase os obstáculos, entretanto, um fato apontado pelos entrevistados como favorável é a alta assiduidade dos membros nas reuniões virtuais e a vontade de todos em colaborar para o melhor atendimento à população idosa no enfrentamento à pandemia.

Por todas as considerações colocadas com respeito às redes de apoio formadas, elas não podem deixar de ser consideradas como facilitadoras da ação do Conselho. E, ainda que de forma indireta, outro facilitador, segundo relatos, tem sido o apoio dos Centros de Referência da Assistência Social (CRAS) e os Centros de Referência Especializados de Assistência Social (CREAS), principalmente dos pequenos municípios, que têm atuado ativamente no enfrentamento à pandemia.

No que concerne aos desafios, o principal, apontado por todos os entrevistados, foi a burocracia governamental, que, em certa medida, impede o acesso ao FEl e que não permite a tomada de iniciativas com agilidade, a exemplo da distribuição de equipamentos de proteção individual cedidos pelo governo do Estado às ILPIs em abril e efetivada em agosto. A burocracia, aliada às dificuldades advindas do teletrabalho dos órgãos estaduais, tem tornado moroso o processo de publicação de documentos expedidos pelo Conselho. Pôde-se acessar a ata da primeira reunião deste ano por meio do Diário Oficial do Estado de Minas Gerais, mas as atas das demais plenárias, assim como o novo Regimento Interno, não haviam sido publicadas até o final de agosto.

Outro desafio relatado é a dificuldade de dar andamento às ações planejadas no ano passado para este ano, principalmente as que requerem presença física, como visitas que seriam realizadas para desenvolvimento de um trabalho junto às ILPIs. Ainda assim, as ações que podem ser realizadas de forma remota têm acontecido, como o estudo para a criação de um selo de identificação das instituições "certificadas". Tem-se também a dificuldade de contato com os órgãos parceiros, que viabilizam a atuação do Conselho com relação a sua função de cumprir e fazer cumprir as normas constitucionais e legais referentes à pessoa idosa e de promover ações junto aos órgãos de segurança e de justiça para que o idoso receba atendimento especial e de qualidade. Um entrevistado relatou que denúncias não puderam ser apuradas e, ou, resolvidas por indisponibilidade de atendimento do Disque 100, da Sedese e da Delegacia Especializada de Proteção e de Crimes Contra o Idoso de Belo Horizonte; ao contrário do apoio encontrado junto aos CRAS e CREAS dos pequenos municípios, principalmente, pois, segundo entrevistados, tem sido difícil conseguir atendimento nos CRAS e CREAS da capital mineira. Com relação ao atendimento da Delegacia Especializada de Proteção e de Crimes Contra o Idoso de Belo Horizonte, no evento do dia 15 de junho, o representante do órgão que estava presente informou que os atendimentos da Delegacia estavam sendo realizados normalmente.

Os entrevistados deixaram claro que o Conselho vem tomando as medidas que julga necessárias e possíveis frente à pandemia, buscando atender à população considerada mais vulnerável, bem como que o 
CEI MG está aberto ao recebimento de demandas de toda a população idosa do estado, para avaliação da situação de outras parcelas desta e para a tomada de decisão no sentido de auxiliá-la no enfrentamento à pandemia da Covid-19.

\section{CONCLUSÕES}

Tendo em conta os dados e as informações levantados pela pesquisa, com relação à estrutura e ao funcionamento do Conselho Estadual da Pessoa Idosa de Minas Gerais, depreende-se que o órgão observa as orientações da literatura voltadas ao aperfeiçoamento dos conselhos como instâncias participativas e que suas atividades não foram paralisadas diante da pandemia da Covid-19, pelo contrário, foi dado foco ao problema e foram realizadas as adequações necessárias para dar prosseguimento às atividades. Em função de determinação estadual e para a proteção da saúde dos seus membros, adotou-se a realização de plenárias virtuais, para tanto, o Regimento Interno foi revisado. O CEI MG tem contado com o empenho dos seus membros e de parceiros, instituições públicas e privadas, assim como membros da sociedade civil preocupados com o bem-estar da pessoa idosa, para o cumprimento das suas atribuições, o enfrentamento da Covid-19 e para superar os desafios impostos pelo cenário de pandemia.

Como iniciativas para o enfrentamento à pandemia, considerando a importância da informação correta, de qualidade e tempestiva, o Conselho, em parcerias, emitiu documentos orientadores para conselhos e prefeituras municipais, também para a população idosa. Ademais, o órgão tem buscado direcionar o atendimento emergencial requerido pelo momento para a parcela da população idosa considerada mais vulnerável, a dos moradores de instituições de longa permanência. E, com o intuito de canalizar suas ações às demandas dessa população, inovou ao requerer a elaboração de um diagnóstico acerca da situação das ILPIs, ao participar da formação e ao utilizar redes de apoio em formato de governança colaborativa para viabilizar ações imediatas. Este fato, além de representar a proatividade e resolutividade do CEI MG, resulta em ganhos para sua atuação futura, pois a Rede de Apoio à Pessoa Idosa, por exemplo, tem prevista a continuidade de suas ações para além da pandemia, o que pode oferecer considerável suporte ao órgão.

Com relação aos desafios do Conselho, destacam-se as questões relativas à comunicação do órgão e aos entraves burocráticos por ele enfrentados. Os problemas de comunicação puderam ser percebidos por meio das primeiras consultas realizadas no site, por buscas em redes sociais, em sítios de busca e pelos depoimentos dos entrevistados; além da desatualização da página oficial e dos perfis em redes sociais, o Conselho enfrenta dificuldades para se comunicar diretamente com seu público-alvo, como os conselhos municipais, por falta de cadastro desses junto ao CEI MG e por não retorno de contatos. Ao final da pesquisa, contudo, observou-se que apesar de se tratar de um procedimento que não depende diretamente do órgão e mesmo durante a pandemia, o Conselho conseguiu efetivar atualizações no site, principalmente com relação à disponibilização de informações acerca da Covid-19. Por outro lado, a divulgação de documentos oficiais ficou prejudicada pelo formato do teletrabalho adotado pelo Estado e persistem os empecilhos para a comunicação com conselhos municipais. Também persiste o bloqueio ao acesso ao Fundo Estadual do 
Idoso, que representa essencial ferramenta para o desenvolvimento de ações pelo Conselho, principalmente diante de situações de emergência, como é o caso da pandemia. A burocracia governamental foi apontada pelos entrevistados como o principal obstáculo à execução de ações planejadas pelo órgão em sua trajetória, não somente durante a pandemia. Espera-se a solução da questão, para que o CEI MG consiga acessar o Fundo e publicar o edital de chamamento público em elaboração e outros que visem captar recursos e aumentar a robustez do FEI.

Conclui-se que o Conselho Estadual da Pessoa Idosa de Minas Gerais tem tomado as medidas cabíveis e possíveis ao órgão neste momento de enfrentamento à pandemia da Covid-19, tendo encontrado neste ambiente de adversidades possibilidades para o seu fortalecimento. Em função de intercorrências cujas soluções não estão ao seu alcance, medidas deliberadas ainda estão pendentes, apesar disso, tem agido no sentido de informar, entender e atender as pessoas idosas, principalmente a parcela mais vulnerável, sem se furtar de receber e buscar atender a demandas de outros grupos da população idosa mineira.

\section{REFERÊNCIAS}

AVRITZER, L.. Instituições participativas e desenho institucional: algumas considerações sobre a variação da participação no Brasil democrático. Opinião Pública, Campinas, v.14, n.1, p.43-64, 2008.

BELEI, R. A.; GIMENIZ-PASCHOAL, S. R.; NASCIMENTO, E. N.; MATSUMOTO, P. H. V. R.. O uso de entrevista, observação e videogravação em pesquisa qualitativa. Cadernos de Educação, v.30, n.1, p.187-199, 2008.

BRASIL. Congresso Nacional. Lei n.10.741, de 10 de outubro de 2003. Dispõe sobre o Estatuto do Idoso e dá outras providências. Brasília: DOU, 2003.

BRASIL. Congresso Nacional. Lei $\mathbf{n . 8 . 8 4 2 , ~ d e ~} 4$ de janeiro de 1994. Dispõe sobre a política nacional do idoso, cria o Conselho Nacional do Idoso e dá outras providências. Brasília: DOU, 1994.

BREDEMEIER, S. M. L.. Conselho do idoso como espaço público. Revista Serviço Social e Sociedade, v.24, n.75, p.84102, 2003.

CARNEIRO, C. B. L.. Conselhos de políticas públicas: desafios para sua institucionalização. Revista de Administração Pública, v.36, n.2, p.277-292, 2002.

DADALTO, L.; MASCARENHAS, I. L.; MATOS, A. C. H.. Salvem também os idosos: etarismo e a alocação de recursos na realidade brasileira de combate ao COVID. Civilistica, v.9, n.1, p.1-19, 2020.

DEBERT, G. G; OLIVEIRA, G. S.. Os dilemas da democracia nos conselhos de idosos. Política Nacional do Idoso: velhas e novas questões. Rio de Janeiro: Ipea, 2016.

DUARTE, J.. Entrevista em profundidade. In: Métodos e técnicas de pesquisa em comunicação. São Paulo: Atlas, 2005. p.62-83.

FONSECA, I. F.. Relações de poder e especificidades do contexto em fóruns participativos. In: Efetividade das instituições participativas no Brasil: estratégias de avaliação. Brasília: Ipea, 2011. p.372.

GARCIA, M. O.; RODRIGUES, P. E. L.; EMMENDOERFER, M. L.; GAVA, R.; SILVEIRA, S. D. F. R.. Usos da Pesquisa Documental em Estudos sobre Administração Pública no Brasil. Teoria e Prática em Administração, v.6, n.1, p.41-68, 2016.

GODOY, A. S.. Introdução à pesquisa qualitativa e suas possibilidades. Revista de Administração de Empresas, v.35, n.2, p.57-63, 1995.

GOHN, M. G.. Conselhos gestores e gestão pública. Ciências Sociais Unisinos, v.42, n.1, p.5-11, 2006.

GBD. Global Burden of Disease Collaborative Network. Global Burden of Disease Study 2017 (GBD 2017): all-cause mortality and life expectancy 1950-2017. Seattle: Institute for Health Metrics and Evaluation (IHME), 2017.

HAMMERSCHMIDT, K. S. A.; SANTANA, R. F.. Saúde do idoso em tempos de pandemia COVID-19. Cogitare Enfermagem, v.25, 2020.

IBGE. Instituto Brasileiro de Geografia e Estatística. Idosos indicam caminho para uma melhor idade. Revista Retratos, 2019.

MALLET, S. M.. Denúncias e ações de enfrentamento à violência intrafamiliar: Conselho Municipal do Idoso de Belo Horizonte 2011-2013. Dissertação (Mestrado em Promoção e Prevenção da Violência) - Universidade Federal de Minas Gerais, Belo Horizonte, 2015.

MARTINS, S.; CKAGNAZAROFF, I. B.; RIBEIRO, A.; COSTA, R. $M$.. Instituições de Longa Permanência para Idosos em Minas Gerais diante da Pandemia da Covid-19. Rede de Apoio à Pessoa Idosa. Belo Horizonte: Secretaria de Estado de Desenvolvimento Social de Minas Gerais, 2020.

MARTINS, S.; RIBEIRO, A.. Das políticas às ações: direitos da pessoa idosa no Brasil. Revista Científica de Direitos 
Humanos, Brasília, v.1, n.1, p.58-81, 2018.

OMS/OPAS. Organização Mundial da Saúde/Organização Pan-Americana da Saúde. Covid-19 Informe-se. OMS/OPAS, 2020.

PEREIRA, P. A.. Controle democrático com garantia de direitos. Brasília: Subsecretaria de Promoção e Defesa dos Direitos Humanos, 2005.

ROCHA, E.. A Constituição cidadã e a institucionalização dos espaços de participação social: avanços e desafios. In: VAZ, F. T.; MUSSE, J. S.; SANTOS, R. F.. 20 anos da constituição cidadã: avaliação e desafios da seguridade social. Brasília: Anfip, 2008. p.131-148.
SÁ-SILVA, J. R.; ALMEIDA, C. D.; GUINDANI, J. F.. Pesquisa documental: pistas teóricas e metodológicas. Revista Brasileira de História \& Ciências Sociais, v.1, n.1, p.1-15, 2009.

SILVEIRA, D. T; CÓRDOVA, F. P.. A pesquisa científica. In: Métodos de pesquisa. 2009. p.31.

VIANNA, H. M.. Metodologia da observação. In: Pesquisa em educação: a observação. 2003.

YIN, R. K.. Estudo de Caso: Planejamento e métodos. Porto Alegre: Bookman, 2015.

A CBPC - Companhia Brasileira de Produção Científica (CNPJ: 11.221.422/0001-03) detém os direitos materiais desta publicação. Os direitos referem-se à publicação do trabalho em qualquer parte do mundo, incluindo os direitos às renovações, expansões e disseminações da contribuição, bem como outros direitos subsidiários. Todos os trabalhos publicados eletronicamente poderão posteriormente ser publicados em coletâneas impressas sob coordenação da Sustenere Publishing, da Companhia Brasileira de Produção Científica e seus parceiros autorizados. Os (as) autores (as) preservam os direitos autorais, mas não têm permissão para a publicação da contribuição em outro meio, impresso ou digital, em português ou em tradução. 